\title{
ARTICLE C3a receptor antagonism as a novel therapeutic target for chronic rhinosinusitis
}

Jennifer K. Mulligan ${ }^{1,2}$, Kunal Patel ${ }^{3,4}$, Tucker Williamson ${ }^{3}$, Nicholas Reaves ${ }^{3}$, William Carroll ${ }^{1}$, Sarah E. Stephenson ${ }^{3}$, Peng Gao ${ }^{5}$, Richard R. Drake ${ }^{5}$, Benjamin A. Neely ${ }^{6}$, Stephen Tomlinson ${ }^{3}$, Rodney J. Schlosser ${ }^{1,7}$ and Carl Atkinson ${ }^{3,4}$

Chronic rhinosinusitis with nasal polyps (CRSwNP) is an inflammatory disease with an unknown etiology. Recent studies have implicated the complement system as a potential modulator of disease immunopathology. We performed proteomic pathway enrichment analysis of differentially increased proteins, and found an enrichment of complement cascade pathways in the nasal mucus of individuals with CRSwNP as compared to control subjects. Sinonasal mucus levels of complement 3 (C3) correlated with worse subjective disease severity, whereas no significant difference in systemic C3 levels could be determined in plasma samples. Given that human sinonasal epithelial cells were the predominate sinonasal source of C3 and complement anaphylatoxin 3a (C3a) staining, we focused on their role in in vitro studies. Baseline intracellular C3 levels were higher in CRSwNP cells, and following exposure to Aspergillus fumigatus (Af) extract, they released significantly more C3 and C3a. Inhibition of complement 3a receptor (C3aR) signaling led to a decrease in Af-induced C3 and C3a release, both in vitro and in vivo. Finally, we found in vivo that C3aR deficiency or inhibition significantly reduced inflammation and CRS development in a mouse model of Af-induced CRS. These findings demonstrate that local sinonasal complement activation correlates with subjective disease severity, and that local C3aR antagonism significantly ameliorates Af-induced CRS in a rodent model.

Mucosal Immunology (2018) 11:1375-1385; https://doi.org/10.1038/s41385-018-0048-x

\section{KEY FINDINGS}

- Heightened sinonasal complement activation is present in CRSwNP, and local sinonasal complement C3 levels correlate with subjective patient disease severity.

- Complement anaphylatoxin antagonism decreases inflammatory infiltrate and local cytokine production associated with murine fungal extract-induced CRS.

- Sinonasal delivery of C3aR antagonist decreases inflammatory infiltrate associated with murine fungal-induced CRS.

\section{INTRODUCTION}

Chronic rhinosinusitis (CRS) results in billions of dollars in healthcare expenditures each year. ${ }^{1}$ Patients with CRS have abnormal immune responses triggered by a variety of infectious agents, airborne toxins, and fungi. ${ }^{1-3}$ The respiratory epithelium is the first point of contact with the outside world and as such epithelial cells serve as relay stations capable of amplifying or augmenting cues received from external stimuli to nearby immune cells located in the sinus mucosa. Upon stimulation, epithelial cells secrete factors that are capable of regulating inflammation, and promoting CRS development. ${ }^{4}$ Recent reviews have described the important regulatory roles of the sinonasal mucosal epithelium in modulating mucociliary clearance, pathogen recognition, and production of innate immune mediators which are designed to cope with local environmental challenges and further orchestrate adaptive immune responses when needed. ${ }^{5,6}$ Breakdown, dysfunction, or uncontrolled activation of any of these pathways can lead to overstimulation of the adaptive immune response, resulting in the pathogenic inflammation characteristic of CRS. ${ }^{5-7}$

Previous studies by our laboratory and others have demonstrated that the complement system, as shown by increased complement deposition and gene transcription, is activated and upregulated in the mucosa of patients with CRS with nasal polyps (CRSwNP).$^{8-14}$ The complement cascade consists of three separate but overlapping pathways: the classical, alternative, and mannose-binding lectin (MBL) pathways. These pathways differ in how complement activation is initiated. Classical pathway activation is initiated by $\mathrm{C} 1 \mathrm{q}$ binding to antibody. The alternative pathway is activated by the generation of $\mathrm{C} 3 \mathrm{~b}$ via hydrolysis or as a by-product of the classical or MBL pathways. The MBL pathway is activated, as its name indicates, when MBL interacts with carbohydrates on the surface of pathogens. Post activation, the classical and MBL pathways are largely similar, but the true

\footnotetext{
${ }^{1}$ Department of Otolaryngology-Head and Neck Surgery, Medical University of South Carolina, Charleston, SC, USA; ${ }^{2}$ Department of Pediatrics, Medical University of South Carolina, Charleston, SC, USA; ${ }^{3}$ Department of Microbiology and Immunology, Medical University of South Carolina, Charleston, SC, USA; ${ }^{4}$ Lee Patterson Allen Transplant Immunobiology Laboratory, Department of Surgery, Medical University of South Carolina, Charleston, SC, USA; ${ }^{5}$ Department of Cell and Molecular Pharmacology and

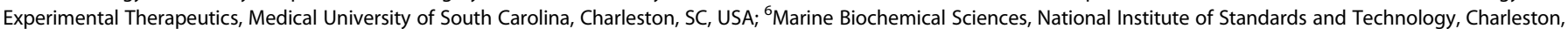
SC, USA and ${ }^{7}$ Ralph H. Johnson VA Medical Center, Charleston, SC, USA

Correspondence: Carl Atkinson (atkinsoc@musc.edu)
}

Received: 31 August 2017 Revised: 5 April 2018 Accepted: 30 April 2018

Published online: 15 June 2018 
convergence point of all three pathways occurs at the formation of a complement 3 (C3) convertase. Thereafter, the complement system serves to elicit inflammatory responses, driving leukocyte chemotaxis (complement anaphylatoxin 3a (C3a), complement anaphylatoxin 5a (C5a)), assisting phagocytosis/opsonization (C3b), and lysing cells via the formation of the membrane attack complex (C5b-C9)(see reviews ${ }^{15,16}$ for an in-depth overview of the complement system). These traditional roles are well described, but recent research has brought to light a variety of additional functions of the complement system and has served to highlight the complex role complement plays in immunologic homeostasis. Complement is viewed as a systemic serum effector system, with the liver producing the majority of soluble complement proteins. ${ }^{17,18}$ Although liver-generated, circulating C3 and C5 are required for the detection and removal of pathogens, ${ }^{17,} 18$ an emerging paradigm suggests that local cell-derived complement activation fragments are key in driving and modulating adaptive T-cell immunity. ${ }^{19-21}$ Studies in organ transplantation and T-cell biology have determined that local cell-specific complement synthesis and release plays a key role in shaping immune responses in the local microenvironment. ${ }^{22-25}$

Complement has been shown to be produced and activated by airway epithelium after stimulation by environment factors such as cigarette smoke and particulate matter, and has been repeatedly proposed as a contributing factor in the pathogenic inflammation of CRS. ${ }^{26-28}$ In addition to increased activation of complement components, such as C1, C3, C5, and C5b-9, complement receptors, such as complement $3 a$ receptor (C3aR) and complement 5 a receptor antagonist $(\mathrm{C} 5 \mathrm{aR}){ }^{29}$ the expression of membrane regulators of complement, decay-accelerating factor, and CD59, have also been demonstrated on epithelial cells. $^{30-34}$ Therefore, excessive complement activation, local complement production, complement receptor signaling, and insufficient complement regulation could contribute to CRS development. However, the underlying importance and scope of complement activation, particularly $\mathrm{C} 3$ activation, in regulating the inflammation associated with CRSwNP has not been extensively studied.

In this study, we investigate the expression and cellular localization of complement component C3, and their relationship with human subjective disease severity. We also evaluate the effects of systemic and sinonasal delivery of a complement receptor antagonist on CRS inflammation and epithelial injury in a murine model. We show that complement is elevated in the local sinonasal microenvironment, produced and stored intracellularly at supranormal levels in CRSwNP epithelial cells, and that C3a receptor antagonism modulates CRS development following systemic or local sinonasal delivery in a rodent model of CRSlike inflammation.

\section{MATERIALS AND METHODS}

Patients enrollment, inclusion, and exclusion criteria

Sinus tissue and nasal mucus was collected at the time of endoscopic sinus surgery. Inclusion criteria include CRSwNP patients that met the diagnostic criteria outlined by the European Position Paper on Rhinosinusitis and Nasal Polyps 2012. ${ }^{35}$ Control sinus tissue was collected from the uncinate process of subjects who were undergoing surgery for repair of cerebrospinal fluid leak repair or removal of non-hormone-secreting pituitary tumor. Exclusion criteria include CRS without nasal polyps, active and former smokers, use of oral steroids or immunomodulatory agents within the preceding 30 days, other immunologic, renal, gastrointestinal, endocrine, or skeletal disorders or pregnancy. Sinus mucosa was processed and used to establish human sinonasal epithelial cell lines or single-cell suspensions (SCS) as previously described. $^{3}, 36,37$ Sinonasal outcome test-22 quality of life questionnaires were completed by patients prior to surgery, as previously described. ${ }^{38}$

Nasal mucus procurement and proteomics screening

Nasal mucus was collected as previously described. ${ }^{39-42}$ Please see Supplemental methods for detailed information on proteomics screening.

In vitro treatments and related measures

SCS were plated at a density of $1 \times 10^{5}$ cells per well in 96-well plates in basal epithelial cell growth medium (BEGM). Aspergillus fumigatus was obtained from Greer Laboratories (Lenoir, NC, USA) and was a combination of mycelial extract and culture filtrate. Aspergillus fumigatus is a ubiquitous fungal antigen, is the most common fungi in the airway, ${ }^{43,44}$ and the most strongly associated with exacerbations in respiratory diseases. ${ }^{45}$ We have previously established an optimal dose of $2 \mu \mathrm{g} / \mathrm{ml}$ (range $0.1-20$ $\mu \mathrm{g} / \mathrm{ml}$ ) which is consistent with other reported in vitro doses ${ }^{46,47}$ and have determined that this dose does not induce cell death, as determined by the lactate dehydrogenase assay. Aspergillus fumigatus was determined to be endotoxin free $(<0.06 \mathrm{EU} / \mathrm{ml})$ by limulus amebocyte lysate assay. ${ }^{37}$ Two micrograms per $\mathrm{ml} \mathrm{Af}$ control (phosphate-buffered saline (PBS)) and/or C3aRA (Calbiochem/EMD Millipore, Burlington, MA, USA) was added to cells for $6 \mathrm{~h}$, after which samples were stained for C3 and C3a as previously described. ${ }^{23}$ A dimethyl sulfoxide vehicle control was also included and found to have no impact on any of the outcomes described herein (data not shown). Samples were assayed immediately using a Guava 8HT flow and analyzed with FCS Express 4.0. Dead cells (7-aminoactinomycin D positive) were excluded from the final data analysis. Marker gates were set using matched isotype controls.

Sinonasal explant tissue from control subjects and CRSwNP patients will be used as the source of all primary HSNEC using our previously described methods.3, 37, 48, 49 Briefly, HSNECs were cultured and treated in serum-free BEGM, used at passage 2 , and were in culture for 10-15 days from the time the sample left the patient to the time the experiment ended. Cultures were established, maintained, purity confirmed, and treated with Af as we have previously described. $3,37,50$ Twenty-four hours post treatment, protein levels, C3 (Genway, San Diego, CA, USA), C3a (BD Biosciences, San Jose, CA, USA), C1q, C4, factor B, C5 (Abcam, USA), and C5b-9 (Quidel, USA) were quantified by ELISA.

Quantitative RT-PCR

Total RNA from control and CRSwNP HSNECs was isolated using a RNeasy MiniKit (Qiagen) according to the manufacturer's instructions. Complementary DNA (cDNA) was synthesized using iScript cDNA Synthesis Kit (Bio-Rad) and mRNA expression of target genes $\mathrm{C} 1 \mathrm{q}, \mathrm{C} 4, \mathrm{C} 3, \mathrm{C} 5, \mathrm{fB}$, and $\mathrm{C} 9$ were determined using MasterCycler RealPlex ${ }^{2}$ PCR System (Eppendorf). Primers used are listed in Supplemental Table I.

Murine model of Af-induced CRS

The murine model of CRS as described by Khalid et al. ${ }^{51}$ was employed utilizing Balb/c and Balb/c C3aR-/- mice (Jackson Laboratories, USA). Eight-week-old mice received an intraperitoneal challenge of Af extract. One week later, mice received intranasal Af extract three times per week for a total of 4 weeks, at which time they were sacrificed $(n=6)$. Unsensitized mice received PBS intranasally three times per week for a total of 4 weeks and were used as controls $(n=6)$. To assess the therapeutic utility of $\mathrm{C} 3 \mathrm{a}$ receptor signaling inhibition, subgroups of mice ( $n=6$ per group) were treated with C3aRA (Calbiochem, USA), by either intranasal (i.n., local) or intraperitoneal (i.p., systemic) route with $1 \mathrm{mg} / \mathrm{kg}$ every 3 days for 4 weeks starting the day after i.n. Af inoculation began. 
Histopathology

Snouts were harvested, fixed in $4 \%$ buffered formalin, decalcified, embedded in paraffin, and sectioned at $5 \mu \mathrm{m}$, and stepped serial sections from all groups were graded as previously described. ${ }^{51}$ Every fifth section containing the vomeronasal organ and nasalassociated lymphoid tissue was examined and graded, using a total of five sections per animal. To characterize the pathology and inflammatory cells, several stains were used, including hematoxylin and eosin for overall morphology and inflammation, chromotrope 2R for eosinophils, and Periodic acid Schiff's alcian blue stain for mucus hyperplasia. Two sections with similar sinus cavities were chosen and examined by an independent researcher blinded to the experimental groups. The number of eosinophils and mast cells was counted under 10 high-power fields from two independent sections, and the average value from four different areas was used for between-group comparisons. The maximal mucosal thickness was measured at the transition zone of the olfactory and respiratory epithelia using an image analysis system (Zeiss Axiovision, USA) using two sections per animal. Epithelial cell goblet cell hyperplasia was quantified using Periodic acid shiff's alcian blue stain and quantified by counting the total number of cells and the total number of mucus-containing goblet cells per unit length of mucosa using two sections per animal as previously described. ${ }^{51,52}$

Sinonasal lavage cytokine analysis

A $22 \mathrm{G}$ catheter was inserted into the tracheal opening in the direction of the choana after a partial tracheal resection under anesthesia, and lavage performed as previously described. ${ }^{52-54}$ C3a, CCL20, GM-CSF, KC, IL-4, IL-5, and IL-13 were measured by ELISA (R\&D Systems, Minneapolis, MN, USA).

Statistical analysis

Statistical analysis was conducted using the GraphPad Prism 6.0 software (La Jolla, CA, USA). Descriptive statistics were used to characterize patient demographic data. A D'Agostino \& Pearson omnibus test was used to determine if data sets were normally distrusted. A $x^{2}$ test was used to determine if there were statistically significant difference in the population composition with regards to gender and race. An unpaired $t$ test was used determine if there were differences in age between controls and patients with CRSwNP. For data in which all groups were normally distributed, a one-way analysis of variance with post hoc, unpaired Student's $t$ - test was used. For analysis where all data sets were not normally distributed, a Mann-Whitney test was used to determine statistically significant differences between indicated groups. A Spearman's correlation analysis was used to determine if a significant correlation existed between patient-matched nasal mucus and plasma C3 and C3a levels.

\section{RESULTS}

Sinonasal, but not circulating, C3 levels correlate with CRSwNP subjective disease severity

Previous studies have shown increased complement fragment C4d, C3d, and C5b-9 deposition, complement 3 receptor expression, and increased complement gene expression $(C 3, C 5$, and $f B$ (alternative pathway)) in the sinonasal mucosa of patients with CRSwNP.8, 9, 29, 55 Given these findings, we assessed whether plasma C3 concentrations were altered in CRSwNP patients, and whether C3 levels correlated with subjective disease severity symptoms. As shown in Table 1, there were no statistically significant differences between control and CRSwNP patient cohorts with regard to age, race, or gender. We observed no significant difference in plasma levels of C3 between controls and patients with CRSwNP (Fig. 1a), and could determine no association between C3 levels and sinonasal outcome test-22 (SNOT22) scores (Fig. 1b).
Recently, there has been a growing emphasis on the role of locally produced effector molecules in disease modulation. Therefore, we next utilized shotgun proteomics to characterize significant protein pathways differentially expressed in CRSwNP by comparing nasal mucus samples from control patients to those with CRSwNP, resulting in the identification of 466 proteins (false discovery rate $<5 \%)$. Differentially abundant proteins were determined using normalized spectral counts and 146 were significantly different, with 24 increased in CRSwNP and 122 decreased (Fig. 1c). Since we were specifically interested in proteins that were increased in CRSwNP, we used these 24 proteins to perform pathway enrichment analysis against the REACTOME database (see Supplemental Table II). The top two identified pathways were initial triggering of complement and complement cascade (Fig. 1d), both of which included C3, complement $4 \mathrm{a}(\mathrm{C} 4 \mathrm{a})$, and complement factor $\mathrm{B}$, which were increased 1.8-fold, 6.7-fold, and 3.8-fold in CRSwNP, respectively. Moreover, while there was no association between plasma levels of C3 and disease severity, conversely there was a positive correlation between nasal mucus C3 levels and poorer subjective disease severity in patients with CRSwNP (Fig. 1e). Together, these data point towards the importance of the complement system in the local sinonasal microenvironment of CRSwNP patients.

HSNEC from patients with CRSwNP have heightened intracellular stores and increased secretion of $\mathrm{C} 3$ and $\mathrm{C} 3 \mathrm{a}$

Given our studies demonstrating associations between disease severity and sinonasal mucus $\mathrm{C} 3$ concentrations, we next investigated whether C3 and C3a was present locally within sinonasal tissues. Using single-cell suspensions of sinonasal tissue explants prepared from CRSWNP and control subjects, we demonstrated that both control and CRSwNP samples contained C3-positive and C3a-

Table 1. Patient demographics

\begin{tabular}{|c|c|c|c|}
\hline \multicolumn{4}{|l|}{ A. Plasma samples } \\
\hline & Control $(n=7)$ & CRSwNP $(n=18)$ & $p$ Value \\
\hline Sex, no. (\%) & & & 0.9428 \\
\hline Men & $3(42.9)$ & $8(44.4)$ & \\
\hline Women & $4(57.1)$ & $10(55.6)$ & \\
\hline Age, mean $\pm S D$ & $47.4 \pm 23.6$ & $40.2 \pm 18.5$ & 0.1629 \\
\hline Race, no. (\%) & & & 0.4090 \\
\hline White & $3(42.9)$ & $11(61.1)$ & \\
\hline African American & $4(57.1)$ & $7(38.9)$ & \\
\hline Other & $0(0)$ & $0(0)$ & \\
\hline SNOT22 score, mean \pm SD & - & $49.3 \pm 27.8[14]$ & - \\
\hline \multicolumn{4}{|l|}{ B. Nasal mucus samples } \\
\hline & Control $(n=6)$ & CRSwNP $(n=11)$ & $p$ Value \\
\hline Sex, no. (\%) & & & 0.7933 \\
\hline Men & $4(66.7)$ & $8(72.72)$ & \\
\hline Women & $2(33.3)$ & $3(27.3)$ & \\
\hline Age, mean $\pm S D$ & $35.5 \pm 14.5$ & $42.45 \pm 21.92$ & 0.4985 \\
\hline Race, no. (\%) & & & 0.6905 \\
\hline White & $4(66.7)$ & $7(63.64)$ & \\
\hline African American & $2(33.3)$ & $3(27.27)$ & \\
\hline Other & $0(0)$ & $1(9.1)$ & \\
\hline SNOT22 score, mean \pm SD & - & $49.625 \pm 20.27[8]$ & - \\
\hline
\end{tabular}

SNOT22 sinonasal outcome test-22, SD standard deviation, [n] number of patients with available SNOT22 scores 

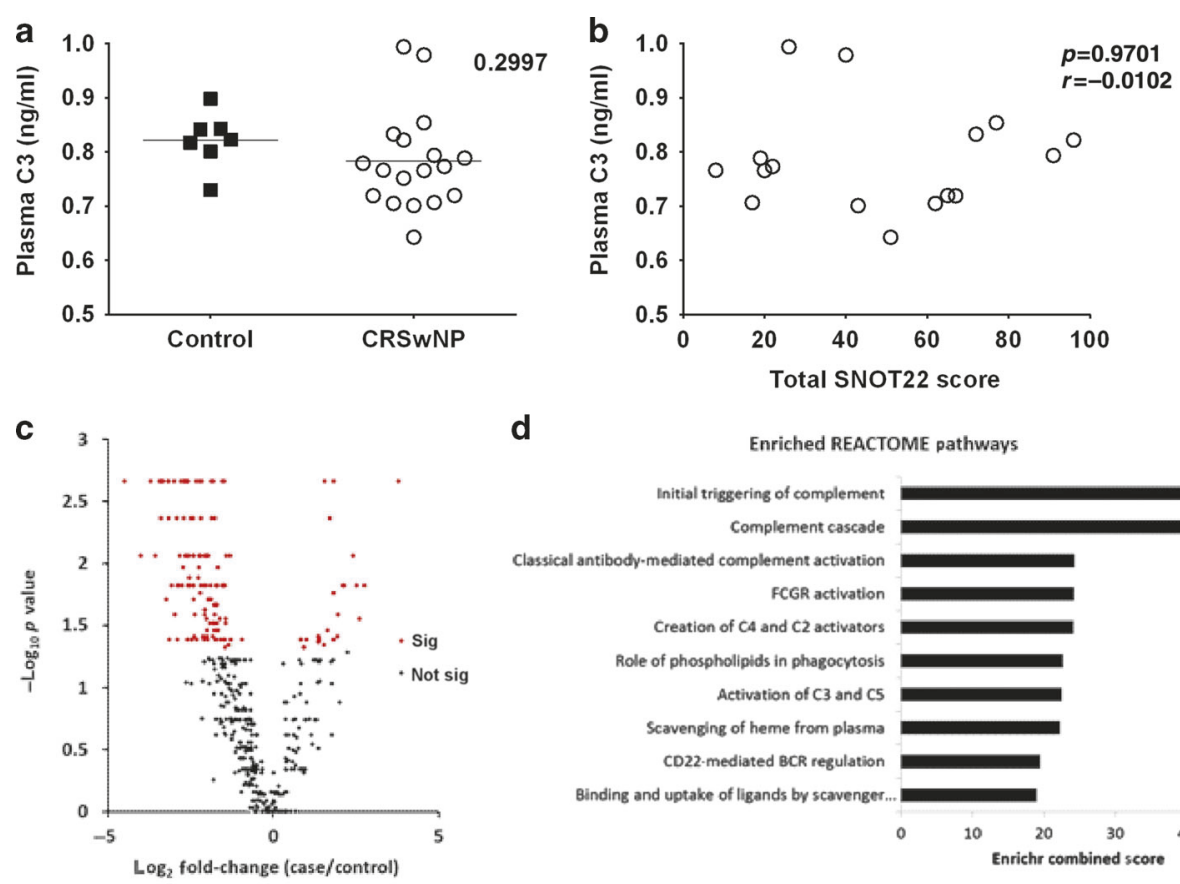

d
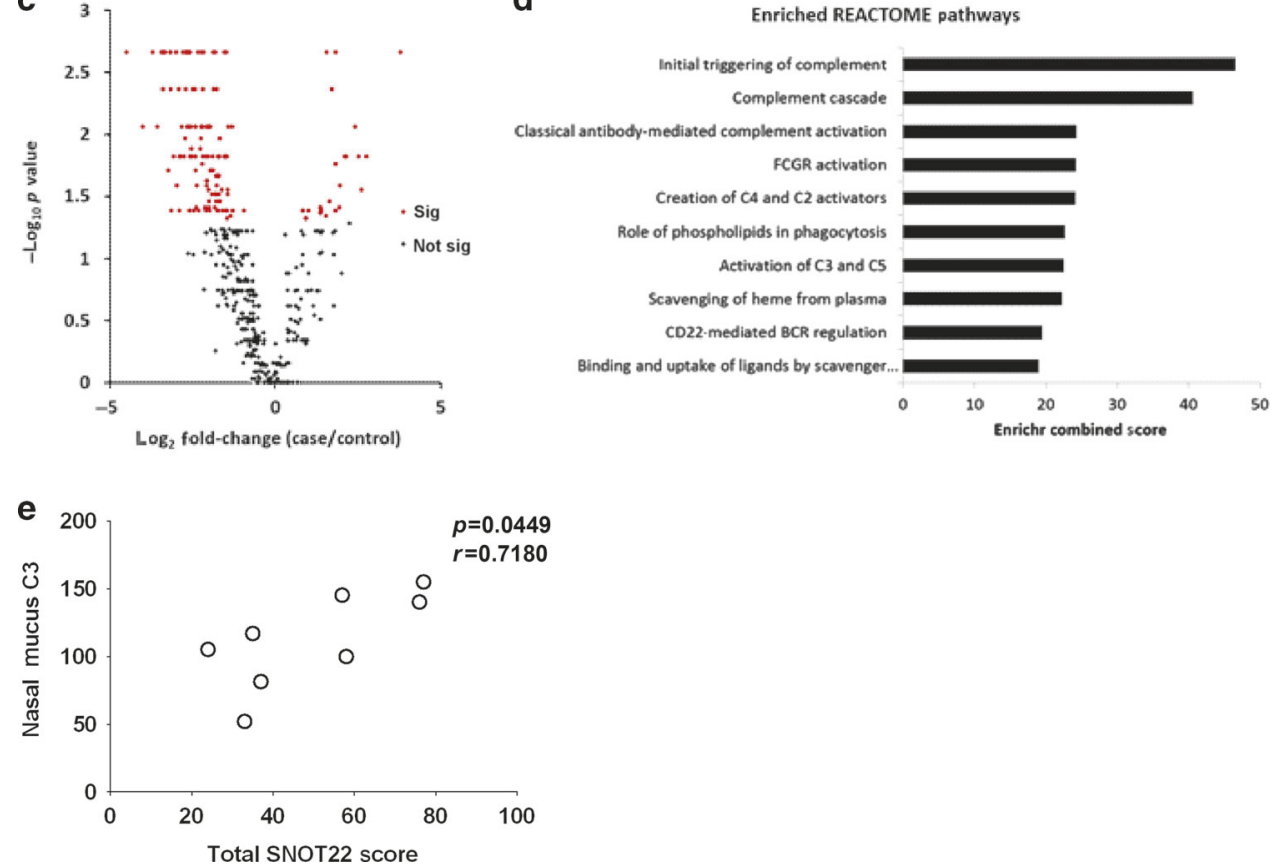

Fig. 1 Local sinonasal complement protein expression is associated with increased subjective disease severity. a Quantification of systemic circulating plasma C3 concentrations in controls and patients with CRSwNP. b Correlation analysis between circulating C3 and subjective disease severity as measured by the sinonasal outcome test-22 (SNOT22). c Volcano plot of shotgun proteomics results. Normalized spectral counts were used to compare protein abundance between CRSwNP and control mucus samples. The majority of the 466 identified proteins were decreased in CRSwNP (77.3\%). d Top 10 Enriched REACTOME pathways. Using just the differentially abundant proteins that were increased in CRSwNP, pathway enrichment was performed against the REACTOME database. The top 10 pathways based on combined score are shown. e Pearson's correlation analysis demonstrating a positive correlation between nasal mucus levels of C3 and subjective disease severity in patients with CRSwNP. NSc normalized spectral counts

positive cells, and that C3 and C3a levels were elevated in CRSwNP as compared to controls (Fig. 2a, b). Furthermore, human sinonasal epithelial cells (HSNECs) were identified as the predominant cell type staining for $\mathrm{C} 3$ and $\mathrm{C} 3 \mathrm{a}$, as determined by positive staining for the epithelial-specific marker, epithelial cell adhesion molecule (EpCam). To further characterize this increase in intracellular C3 and determine the source of $\mathrm{C} 3$, we performed quantitative real-time reverse transcriptase PCR (qRT-PCR) studies on HSNECs from control and CRSwNP patients. mRNA levels of key complement factors $\mathrm{C} 1 \mathrm{q}$ (classical pathway), C4 (classical and lectin pathways), C3, C5, fB, and C9 were analyzed. In keeping with previous studies of epithelial cells of the respiratory system, ${ }^{56}$ we could determine no C9 expression in HSNECs from either group. In support of our flow cytometry data, we demonstrate increased $\mathrm{C} 3$ gene expression in HSNECs of CRSwNP, as compared controls, along with increases in other complement components $\mathrm{C} 4, \mathrm{C} 5$, and $\mathrm{fB}$. We were unable to detect any gene expression for $\mathrm{C} 1 \mathrm{q}$ in HSNECs.

To determine whether the increase in C3 and C3a noted was associated with increased surface or intracellular stores of $\mathrm{C} 3 / \mathrm{C} 3 \mathrm{a}$, we performed flow cytometry on HSNECs, cultured in serum-free conditions, from control and CRSwNP patients using samples that were permeabilized and non-permeabilized, as previously described. ${ }^{23}$ Similar to the results observed in our sinonasal explant studies, and keeping with our previously reported RT-PCR data, ${ }^{9}$ we observed higher C3 levels in HSNEC from patients with CRSwNP than those from controls (Fig. 3a), and determined that $94 \%$ of the C3 that was identified was intracellularly located. C3 was present at significantly lower levels in control samples, but similar to CRSwNP, the majority of C3 present (84\%) was intracellularly located. C3a levels were similar between control and CRSWNP HSNEC, and were found in similar amounts, on the cell surface and within the intracellular compartment (Fig. 3b).

To investigate whether these increased intracellular stores were due to a failure to release $\mathrm{C} 3$ into the surrounding tissues or to increased synthesis by CRSwNP epithelial cells, we measured C3 concentrations in the media supernatants within our culture system, which contained no serum. We showed that at baseline, C3 media concentrations were significantly elevated in CRSwNP HSNEC culture media as compared to control epithelial cells (Fig. 3c). Following $24 \mathrm{~h}$ of stimulation with the ubiquitous fungal allergen Aspergillus fumigatus (Af), there was a dose-dependent increase in the secretion of C3 and C3a by CRSwNP cells, as compared to controls (Fig. 3c). C3a levels were undetectable in the supernatants of unstimulated CRSwNP and control HSNEC cultures 

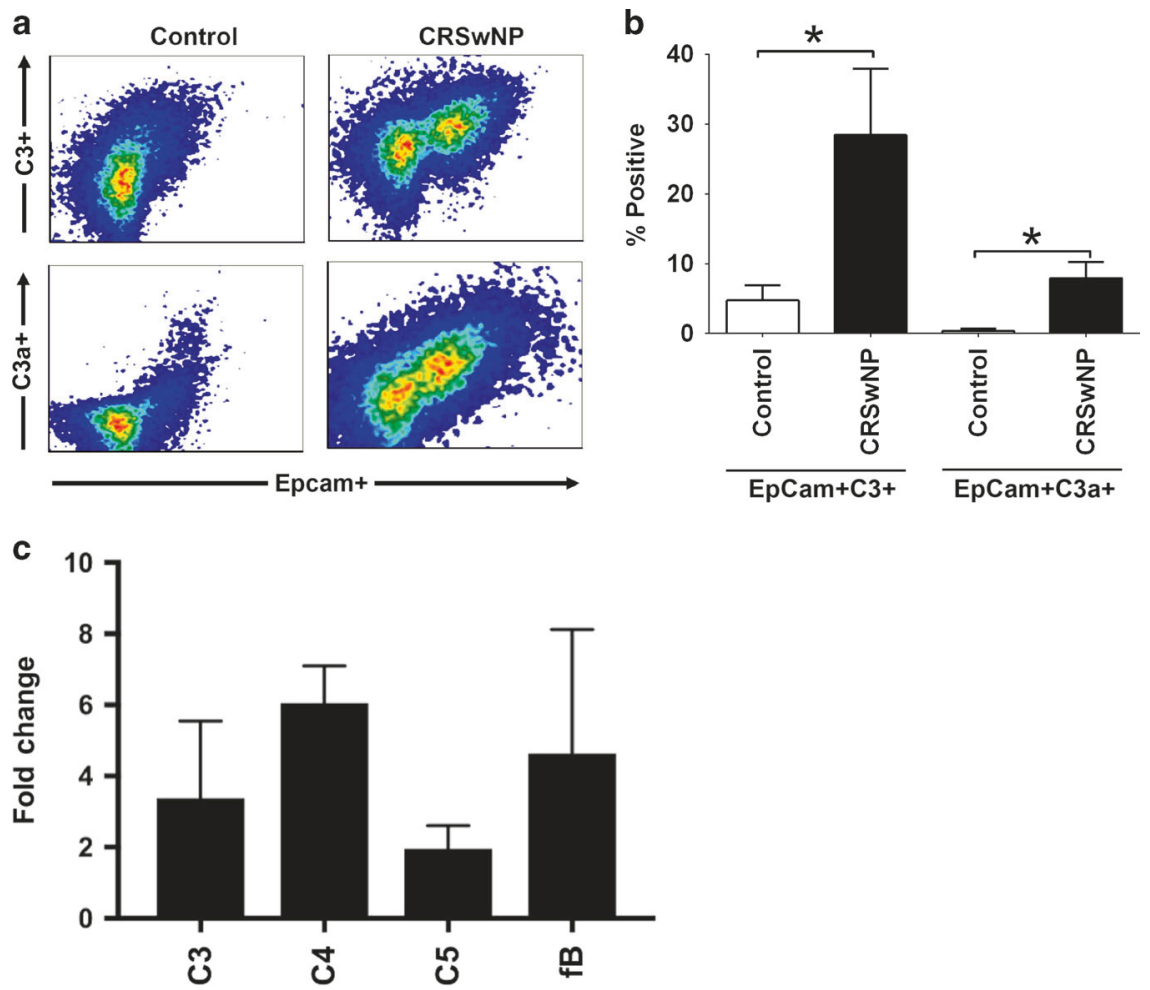

Fig. 2 Sinonasal tissues from patients with CRSwNP have heightened levels of C3 and C3a. a Single-cell suspensions were prepared by mechanical separation and stained for the epithelial cell marker EpCAM. Following permeabilization cells were immunostained for C3 and C3a. Note that human sinonasal epithelial cells were the predominate cell type staining positively for C3 and C3a. b Quantification of the percent of viable cells double positive for EpCam and C3 or C3a. Note the significant increases seen in EpCam + C3 and C3a expression sinonasal epithelial cells in patients with CRSwNP. $n=4$ per group. Statistics shown are unpaired Student's $t$ test between indicated groups. ${ }^{*} p<0.05$. c Complement mRNA levels were measured in control and CRSwNP HSNECs by qRT-PCR. Relative HSNEC expression of C3, C4, C5, and $\mathrm{fB}$ was assessed and expressed as a fold change in CRSwNP as compared to control HSNEC expression. Note the increase in C3, C4, C5, $\mathrm{FB}$, and $\mathrm{fH}$. No gene expression for $\mathrm{C} 1$ or $\mathrm{C} 9$ could be detected in HSNECs from either group (data not shown). $n=5-8$ per group

(Fig. 3d). Again, upon Af stimulation there was a significant increase in C3a concentrations within the supernatant of CRSwNP as compared to controls (Fig. 3d). Stimulation of HSNEC from control patients with Af had little to no impact on C3 or C3a release. Further analysis of key complement pathway proteins, $\mathrm{C} 1 \mathrm{q}, \mathrm{C} 4, \mathrm{fB}, \mathrm{C} 5$, and sC5b-9 (terminal pathway), demonstrated dose-dependent increases in $\mathrm{C} 4, \mathrm{fB}$, and $\mathrm{C} 5$ (Fig. 3e-g). $\mathrm{C} 1 \mathrm{q}$ and sC5b-9 were undetectable in the culture supernatant, which is not unsurprising given our mRNA expression analysis. Together, these data suggest that CRSwNP HSNECs have an increased complement activity phenotype and have the ability to secrete increased amounts of $\mathrm{C} 3$ into the microenvironment, both at baseline and post Af stimulation, which may explain the increased C3 mucus concentrations noted in our proteomic and enzyme-linked immuno sorbent assay (ELISA) studies.

Human T-cell studies have suggested that intracellular tonic levels of $\mathrm{C} 3 \mathrm{a}$ are required for $\mathrm{T}$ cell survival and function, ${ }^{23}$ with stores of intracellular complement maintained via an autocrine loop induced by $\mathrm{C} 3 \mathrm{a}$ ligation to its receptor (C3aR). We therefore examined the expression of C3aR on control and CRSWNP HSNECs. We demonstrated that C3aR expression is elevated in CRSwNP patients at baseline as compared to controls (Fig. 4a, b). Given these data, we next examined if inhibition of $\mathrm{C} 3 \mathrm{a}$ signaling could diminish Af-induced increases in HSNEC C3 release. While C3aR antagonist (C3aRA) had no statistically significant impact on baseline HSNEC C3 secretion, it was able to significantly reduce Afstimulated C3 release to near control levels (Fig. 4c).

Af stimulation induces $\mathrm{C} 3$ activation in vivo

We next assessed the impact of Af stimulation on complement activation in vivo to determine whether Af could promote localized sinonasal complement activation. Utilizing mice with developed CRS that had been allergen sensitized for 4 weeks with Af, we analyzed sinonasal C3 complement activation. Immunohistochemical studies, with an antibody to the long-lived C3 cleavage fragment $\mathrm{C} 3 \mathrm{~d}$, showed that direct intranasal exposure of Af lead to significant C3d deposits within the microvasculature and on epithelial cells (Fig. 5a), consistent with that seen in human studies. ${ }^{9}, 14,55$ C3d deposition was not evident in saline controlchallenged mice (Fig. 5b).

In concordance with immunohistochemical studies, nasal lavage fluids had significantly elevated C3 activation product, $\mathrm{C} 3 \mathrm{a}$, following Af stimulation (Fig. $5 \mathrm{c}$ ). It is thought that $\mathrm{C} 3$ release and synthesis is in part mediated by an autocrine feedback loop, whereby $\mathrm{C} 3 \mathrm{a}$ interacts with $\mathrm{C} 3 \mathrm{aR}$ to promote $\mathrm{C} 3$ and $\mathrm{C} 3 \mathrm{a}$ synthesis and storage. ${ }^{23}$ To examine this in vivo, we pre-treated mice with intranasally $\mathrm{C} 3 \mathrm{a}$ receptor antagonist (C3aRA)-challenged mice with Af $24 \mathrm{~h}$ later. After an additional $72 \mathrm{~h}$, we measured nasal lavage levels of C3a. Pre-challenged C3aRA treatment led to a significant reduction in $\mathrm{C} 3$ a levels, suggesting that local sinonasal C3a release is in part mediated via an autocrine $\mathrm{C} 3 \mathrm{a} / \mathrm{C} 3 \mathrm{aR}$ axis (Fig. $5 \mathrm{c}$ ). Of note, systemic administration of C3aRA had no impact on local C3a levels following acute Af challenge (data not shown).

Af and C3a sinonasal inoculation promotes inflammation and type 2 cytokine expression and are inhibited by $\mathrm{C} 3 \mathrm{aR}$ antagonism

To further explore the interplay between Af and $\mathrm{C} 3 \mathrm{a}$ in terms of sinonasal inflammation, we acutely challenged mice that had been exposed to 4 weeks of Af challenge and that had developed CRS, with either Af or C3a (50 ng i.n.), and 3 days later analyzed lavage samples for inflammatory chemokine/cytokines and type 2 cytokines levels. Chemokine ( $C-C$ motif) ligand 20 (CCL20), 


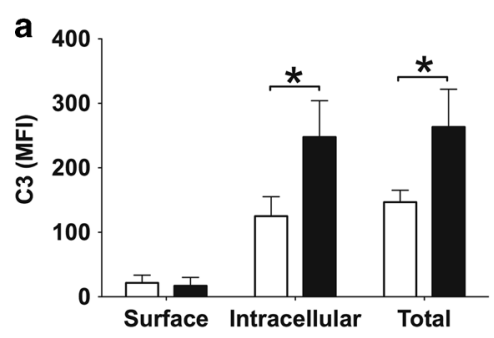

C

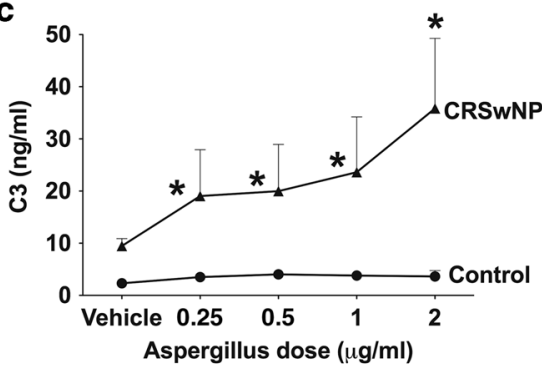

e

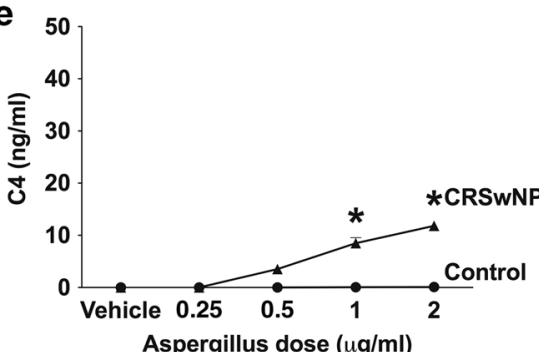

g

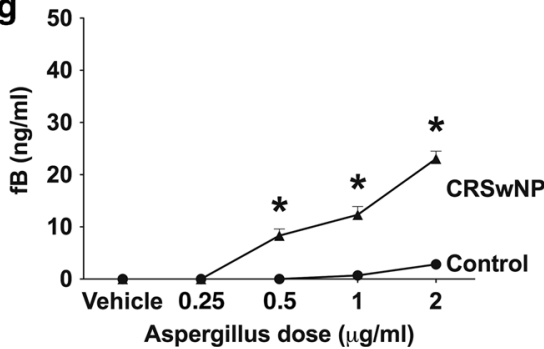

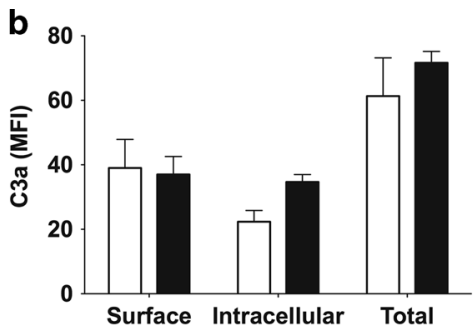
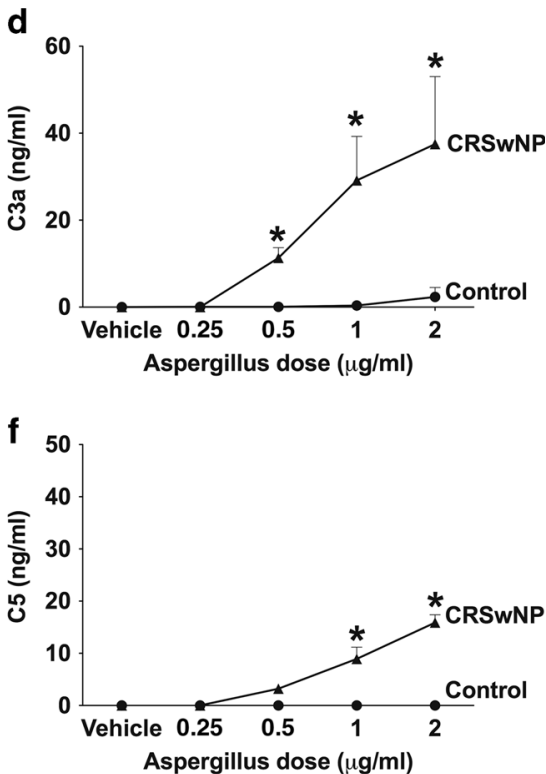

Fig. 3 CRSwNP-derived HSNECs have a heightened release of C3 and C3a upon Aspergillus fumigatus (Af) extract challenge. Surface, intracellular, and total C3 (a) and C3a (b) levels in unstimulated HSNEC show that CRSwNP HSNECs have increased intracellular stores of C3 as compared to those from control subjects. ${ }^{*} p<0.05$ between indicated groups. ELISA measurement of (c) C3, (d) C3a, (e) C4, (f) C5, and (g) fB in HSNEC culture supernatants following exposure to increasing doses of Af extract. Note that CRSwNP cells had significantly more C3, C3a, C4, $\mathrm{C} 5$, and $\mathrm{fB}$ as compared to control. Values shown are mean $\pm \mathrm{SD}$. ${ }^{*} p<0.05$ vs. dose-matched control. $n=4$ per group

keratinocyte chemoattractant (KC) (human interleukin-8 (IL-8) equivalent), granulocyte macrophage-colony-stimulating factor (GM-CSF), IL-4, IL-5, and IL-13 were selected because they are upregulated in CRSwNP patients and have been shown to be associated with more severe disease. ${ }^{39,}$ 57-61 Both Af and C3a exposure promoted robust GM-CSF, CCL20, KC, IL-4, and IL-5 expression as determined by ELISA (Fig. $5 \mathrm{~d}$ ). While IL-13 was measured, we could determine no detectable levels in our assay system. Interestingly, pre-treatment of mice with C3aRA, prior to Af and $\mathrm{C} 3$ a challenge, significantly reduced cytokine levels to that seen in control mice for all measured analytes (Fig. $5 \mathrm{~d}$ ).

C3aR deficiency or antagonism inhibits CRS development To explore the therapeutic potential of our findings, we employed a commercially available C3aRA, which we delivered systemically by i.p. injection, or locally by i.n. route. Both C3aR deficiency and C3aRA, irrespective of route of delivery, reduced histologic evidence of sinonasal respiratory epithelial injury and inflammation as compared to untreated controls (Fig. 6). We also observed decreased inflammatory cell infiltrates, eosinophil numbers, goblet cell hyperplasia, and epithelial thickness in C3aR-deficient $(\mathrm{C} 3 \mathrm{aR}-/-)$ or $\mathrm{C} 3 a \mathrm{R}$-inhibited mouse (Fig. 7a-d). Interestingly, localized C3aRA deliver to the sinus cavity by i.n. route was similarly protective as both systemic antagonism and complete C3aR deficiency.

\section{DISCUSSION}

CRSWNP is a disease characterized by uncontrolled inflammation that is often refractory to current standard treatments. While many immune mechanisms have been studied in the development and treatment of CRS, no single pathway has been shown to be disease causing or modifying. Innate and adaptive immune factors undoubtedly synergize to promote disease, and as such targeting 

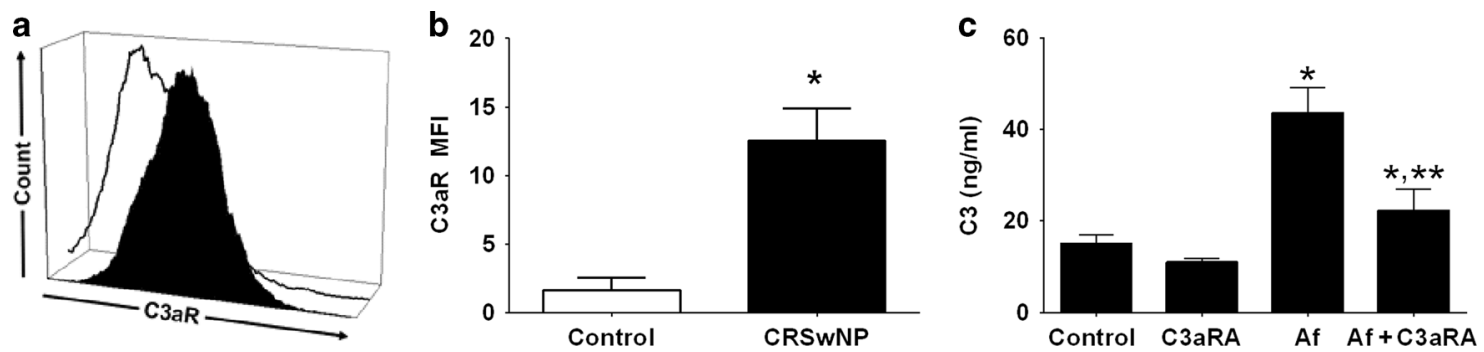

Fig. 4 Human sinonasal epithelial cells (HSNEC) from patients with CRSwNP have elevated expression of C3aR. a Representative histogram showing epithelial surface C3aR expression by control HSNEC (open histogram) and HSNECs from patients with CRSwNP (black histogram). $\mathbf{b}$ Quantification of C3aR expression. Note the increase of C3aR expression in CRSwNP as compared to control epithelial cells. c Inhibition of C3a signaling with a C3a receptor antagonist (C3aRA) blocks Af-induced increases in HSNEC secretion of C3. * $p<0.05$ vs. control. ${ }^{* *} p<0.05$ vs. Af treatment. For $\mathbf{a}, \mathbf{b}, n=3$ per group. $\mathbf{c}$ Mean \pm SD from experiments with four different control HSNEC cultures

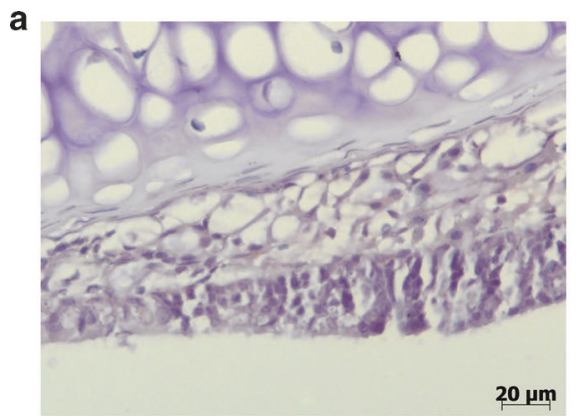

C
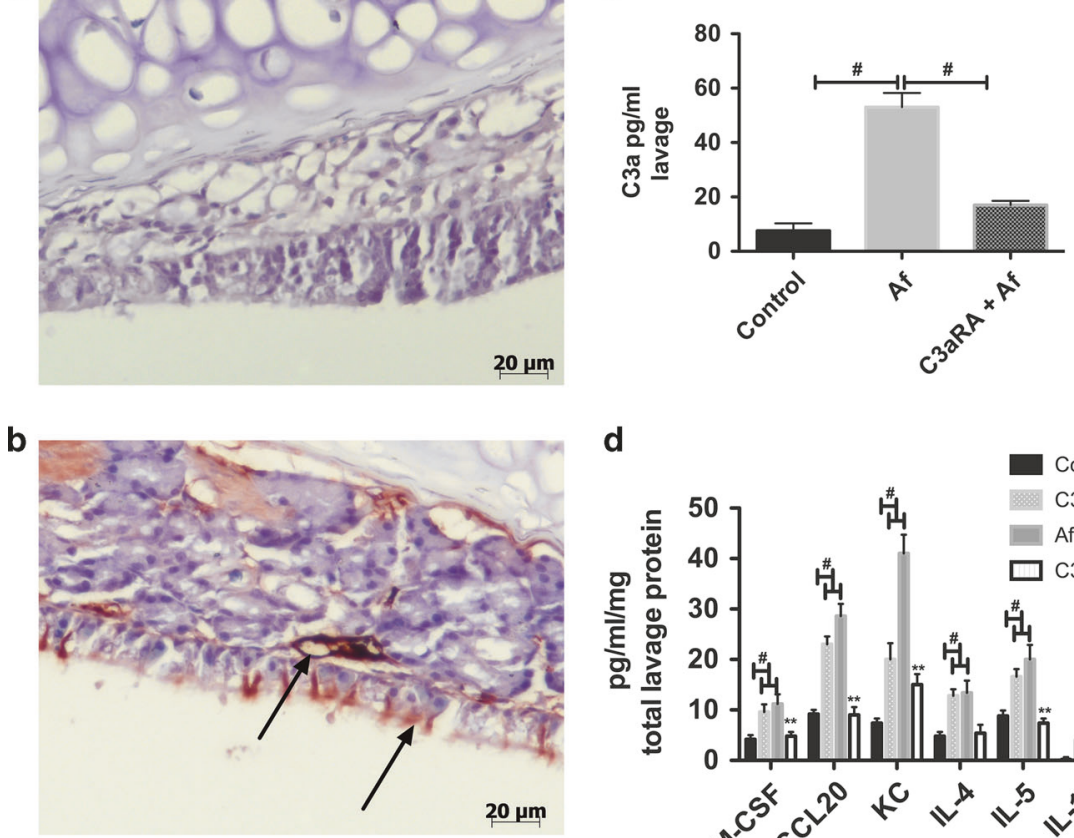

d

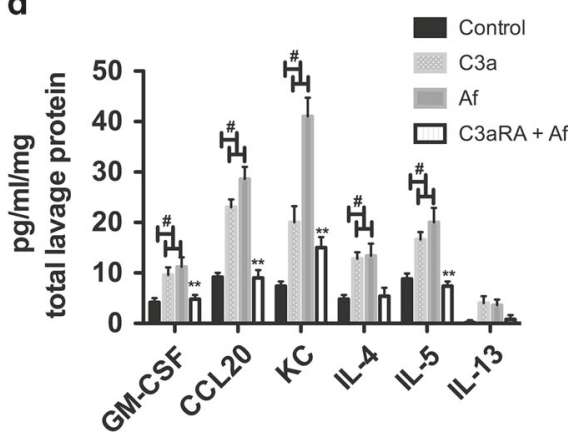

Fig. 5 Intranasal Aspergillus fumigatus (Af) extract challenge activates complement and promotes inflammation within the sinonasal cavity, and can be ameliorated by C3a receptor antagonism (C3aRA). Balb/c mice that received 4 weeks of Af allergen challenge and were confirmed to have CRS-like inflammation were challenged with Af intranasally to investigate dynamic complement activation. Seventy-two hours post final Af intranasal challenge heads were isolated for immunohistochemistry detection of C3d (a, b) and lavage samples taken for C3a ELISA. Note that Af induced membrane complement deposition as marked by the long-lived membrane-associated C3 activation fragment, C3d. C3d deposition was increased in Af-CRS mice (b, arrows) as compared to control (a). Confirmation of local C3 activation was seen in nasal lavage fluids with increased $\mathrm{C} 3 \mathrm{a}$ anaphylatoxin concentrations seen $72 \mathrm{~h}$ post Af inoculation, which was significantly reduced by pre-treatment with C3aRA (c). ( $\left.{ }^{\#} p<0.05\right)(n=4-6)$. ELISA measurement of inflammatory chemokines/cytokines CCL20, GM-CSF, and KC, and type 2 cytokines IL-4, IL-5, and IL-13 post inoculation with either Af or C3a, C3aRA-pre-treated Af-inoculated mice. Note that all challenges induce cytokine production, with the exception of IL-13 (data not shown), and that C3aR antagonism pre-treatment significantly reduces all measured cytokine/chemokines as compared to Af alone $\left({ }^{*} p<0.05\right.$, control vs. treatment groups, ${ }^{* *} p<0.01$ GM-CSF, CCL20, KC, IL-4, IL-5 treatment group vs. C3aRA treatment) $(n=4-5)$

pathways that can modify both systems is an approach that may well prove efficacious. One such pathway that we investigated here is the complement system. The complement cascade can induce cell death, promote inflammation, and program adaptive immunity. Given these broad-ranging functions, we analyzed plasma and local concentrations of C3 in CRSwNP patients to determine whether an association existed between $\mathrm{C} 3$ levels and subjective disease severity. Plasma C3 levels were not associated with CRSwNP subjective disease severity, an observation in line with previous findings. ${ }^{32,}{ }^{33}$ While some studies have demonstrated increased plasma C3 concentrations, as compared to controls, these increases were not associated with disease severity. ${ }^{32,}{ }^{33} \mathrm{C} 3$ is an acute phase reactant, and consequently while measurements of plasma concentrations are often elevated in chronic inflammatory conditions, they may also be depressed by increased catabolism that synthesis of new C 3 is temporally not able to restore. Therefore, differences in sample preparation, time of sample procurement, and stage of disease in the patient population may explain why we saw no difference in plasma concentrations in CRSwNP patients as compared to controls. Changes in other complement components that correlate with disease severity have been described, with deficiency in C4A and 

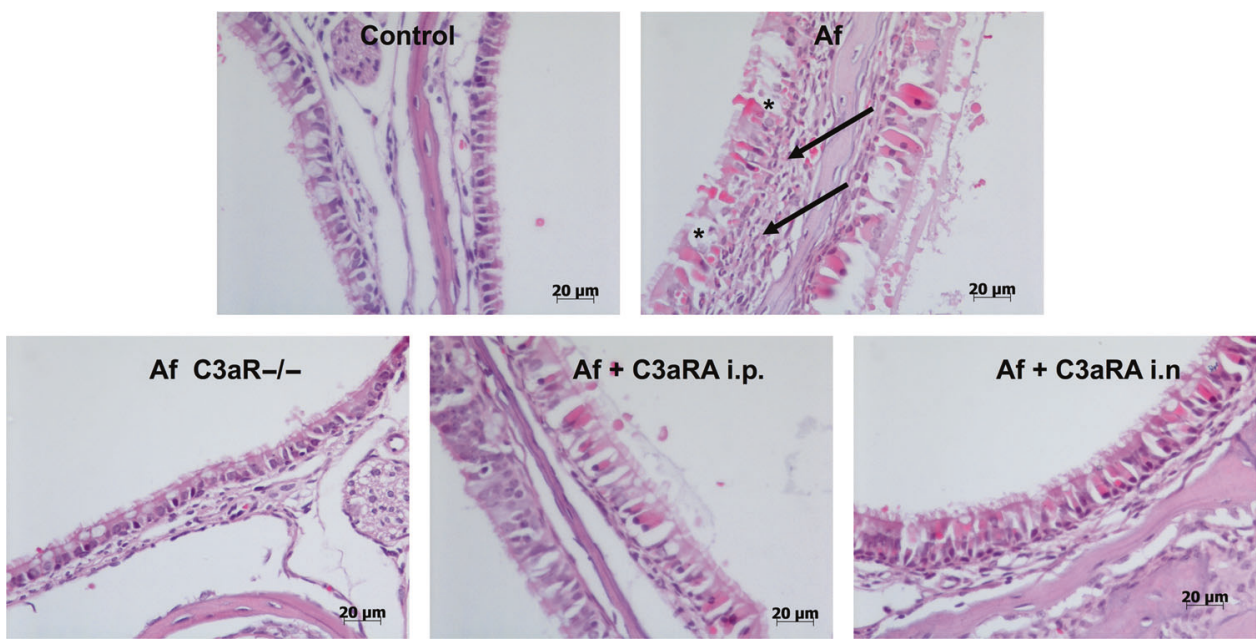

Fig. 6 Complement C3a receptor deficiency or therapeutic antagonism reduce sinonasal inflammation and epithelial remodeling. Hematoxylin-stained and eosin-stained sections of sinus mucosa from animals in each treatment group. Note the extensive sub-epithelial inflammation characterized by eosinophil, macrophage, and neutrophil infiltrates in Af-challenged mice as compared to control, C3aR-/and treatment groups (arrows). Further note the more pronounced mucus-producing cells lining the sinus lumen $\left(^{*}\right)$. Images representative of $n=6$ in each group, scale as shown
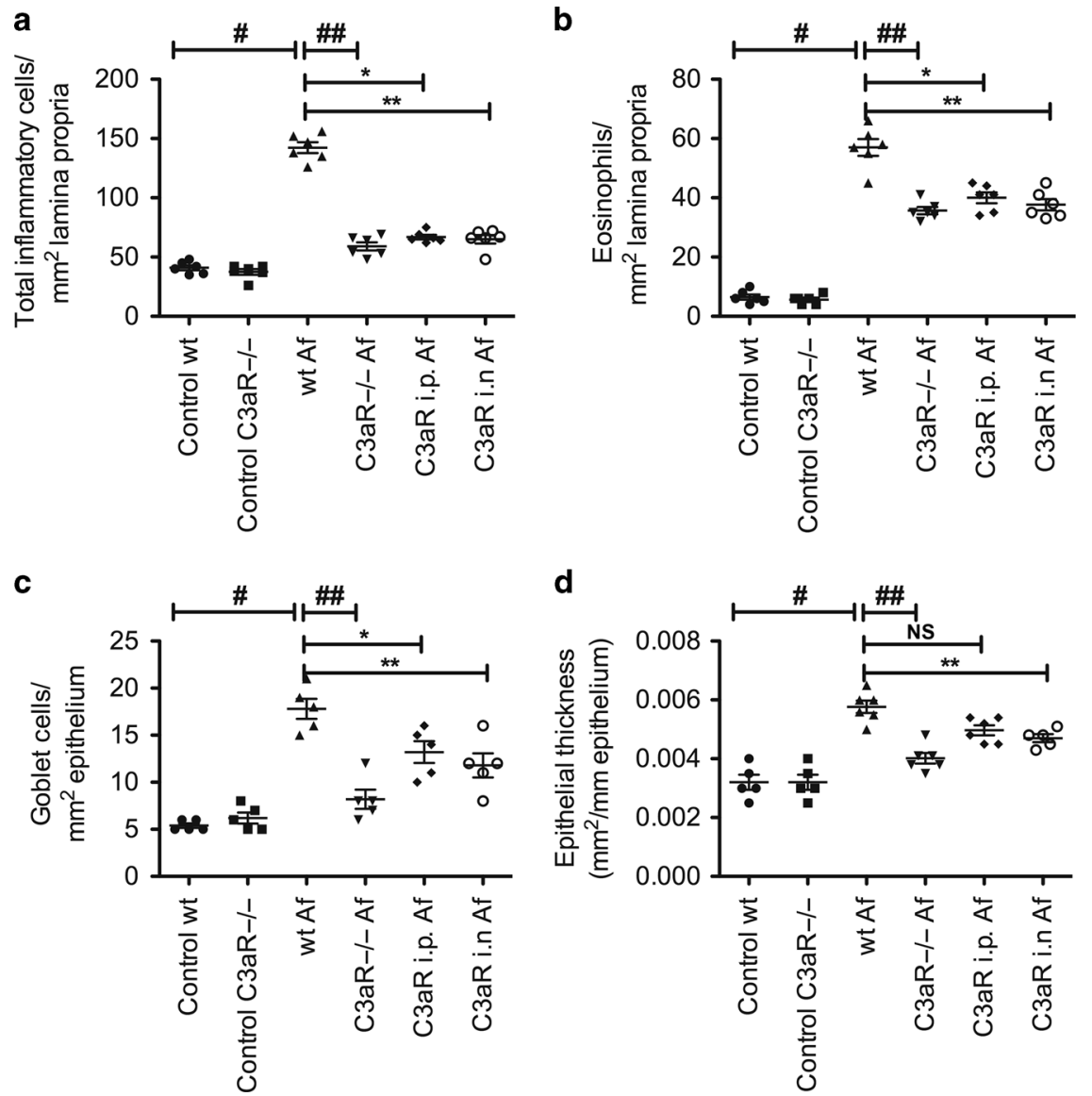

Fig. 7 Quantification of sinonasal inflammation, epithelial injury, and goblet cell hyperplasia demonstrates the protective effect of complement C3a receptor deficiency and therapeutic antagonism. a Inflammatory cell infiltrate, b eosinophil accumulation, c goblet cell hyperplasia, and $\mathbf{d}$ epithelial injury/thickness. Data are expressed as mean \pm SE. All statistical analysis are pairwise comparisons, control wild-type vs. wild-type Af $\left({ }^{\#} p<0.001\right)$, wild-type Af vs. C3aR-/- Af $\left({ }^{\#} p<0.01\right)$, wild-type Af vs. C3aR i.n. $\left({ }^{*} p<0.01\right)$, wild-type Af vs. C3aR i.p. $\left.{ }^{* *} p<0.01\right)$

MBL associated with increased disease, likely due to increased susceptibility to infection. ${ }^{32,34}$

While $90 \%$ of all complement proteins are produced within the liver, there is a growing appreciation that complement synthesized in the microenvironment is instrumental in orchestrating local immune responses. Novel studies by Liszewski et al. ${ }^{23}$ highlighted that lymphoid, myeloid, and non-myeloid cells can synthesize, store, and release the active C 3 components C $3 a$ and 
C3b. Given these findings, we hypothesized that local complement production may be increased in patients with CRSwNP and may exacerbate disease. Our mucus proteomic pathway enrichment analysis identified two significant pathways, the initial triggering of complement and complement cascade pathways, both of which included $\mathrm{C} 3, \mathrm{C} 4 \mathrm{a}$, and $\mathrm{fB}$. The approximate twofold changes we noted in $\mathrm{C} 3$ were in keeping with a previous proteomic study that utilized nasal mucus samples from 29 allergic rhinitis patients. ${ }^{62}$ When analysis of local sinonasal mucus sample C3 levels were correlated to SNOT22 scores, unlike plasma concentrations, we demonstrated a positive association between C3 levels and disease severity, suggesting that locally elevated C3 plays a role in CRSwNP.

We analyzed sinonasal tissues and observed that the predominant cell type positive for $\mathrm{C} 3$ and C3a were HSNECs. The epithelium plays a central role in controlling inflammation in the sinonasal cavity, and is important in modulating immune cell functions, and therefore the production of complement by HSNEC may be important in modulating immunity. Furthermore, previous studies in the lower respiratory tract have shown that bronchial epithelial cells can produce and release $\mathrm{C} 3$ in response to proinflammatory cytokine stimulation. ${ }^{63}$ Analysis of HSNECs revealed intracellular stores of $\mathrm{C} 3$ that were present at supranormal levels in CRSwNP, as compared to controls. The higher concentrations of C3/C3a that we found in HSNEC with CRSwNP are in part corroborated by our previous PCR studies where we demonstrated increased C3 mRNA transcripts in CRSwNP, ${ }^{9}$ and could account for the intrinsically pro-inflammatory microenvironment seen in CRSwNP patients. To provide further support of our flow cytometry analysis, we performed complement mRNA analysis and demonstrate that $\mathrm{C} 3$, as well as $\mathrm{C} 4, \mathrm{C} 5$, and $\mathrm{fB}$, are upregulated in CRSwNP as compared to controls. Interestingly, we showed that early pathway activation factor $\mathrm{C} 1 \mathrm{q}$ and terminal pathway C9 were not expressed at the gene level in HSNEC epithelial cells at baseline. When stimulated with the ubiquitous fungal antigen $A f, \mathrm{C} 3$ and C3a was released in greater quantities by CRSwNP HSNEC. Taken together, these data show for the first time the presence of intracellular stores of C3 and C3a in HSNECs, which may contribute to the intrinsically pro-inflammatory nature of HSNECs from patients with CRSwNP. The presence and role of epithelial intracellular complement in injury modulation is an evolving concept, and while it is difficult to delineate the relative contribution of locally and systemically derived complement sources in disease progression, the presence of $\mathrm{C} 3$ at supranormal levels in the local microenvironment could well orchestrate a heightened pro-inflammatory milieu capable of exacerbating inflammation, and thus disease.

While our data and that of others ${ }^{23,64,65}$ support the hypothesis that activated cellular stores of complement can reside within discrete cellular compartments within cells, a recent study has suggested that these stores reflect an active transportation of complement through the cell from serum sources as opposed to local cell production. ${ }^{66}$ Elvington et al. ${ }^{66}$ eloquently demonstrated that intracellular stores of complement are the result of uptake from serum, and that cells, particularly those exposed to fluid phase complement components, actively cycle complement proteins between the extracellular and intracellular space. In our studies, HSNECs were cultured and maintained in a serum-free system devoid of exogenous complement, and are cultured for up to 2 weeks prior to performance of presented experiments, thus making it unlikely that the intracellular stores seen in these studies are derived from passive uptake of serum complement, but rather reflect a de novo local production of complement by barrier epithelial cells. Taken together, these studies highlight the important role of locally generated complement and its activation in injury, cytokine production, and disease pathogenesis.

Interestingly, while baseline levels of C3/C3a were significantly different between CRSwNP and controls, only CRSwNP responded to escalating doses of Af stimulation by releasing $\mathrm{C} 3, \mathrm{C} 3 \mathrm{a}, \mathrm{C} 4, \mathrm{C} 5$, and $\mathrm{fB}$. The mechanism/s by which Af results in $\mathrm{C} 3$ release has not been determined, but it has been postulated that responses to allergens may be mediated by allergen receptors present on diseased epithelial. ${ }^{67,68}$ Whether these receptors are differentially expressed on HSNEC from CRSWNP and controls has not been investigated, but given our data it is an area for future investigations. An alternative explanation for these differences could be directly related to differences in basal complement activity between controls and CRSwNP. Aspergillus fumigatus can activate complement independently of canonical pathways of activation. For example, although Af antibodies have been identified, there are no antibodies in our in vitro system, and thus it is likely that components of the mycelial Af wall activate $\mathrm{C} 3{ }^{69}, 70$ generating $\mathrm{C} 3 \mathrm{a}$. Given the increased presence of both $\mathrm{C} 3$ and C3a in CRSwNP, it is plausible that cleavage of C3 leads to increased C3a signaling and stimulation of C3 production. C3a is a potent chemotactic peptide, can induce pro-inflammatory cytokine release via engagement with its receptor $\mathrm{C} 3 \mathrm{aR}$, and can further promote $\mathrm{T}$ effector cell proliferation and T-regulatory cell inhibition; all factors that would propagate CRSwNP. In particular, complement anaphylatoxins such as C3a have the ability to skew $\mathrm{T}$ cell responses and suppress T-regulatory cell functions. ${ }^{21,71-76}$ In human $\mathrm{T}$ cell studies in which C3a intracellular stores were first described, it was postulated that $\mathrm{C} 3 \mathrm{a}$ acts in an autocrine fashion to promote $\mathrm{C} 3 / \mathrm{C} 3 \mathrm{a}$ production via increased C3aR expression. ${ }^{23}$ Blockade of $\mathrm{C} 3$ a signaling in T cells led to reduced intracellular and extracellular release of $\mathrm{C} 3 / \mathrm{C} 3 a{ }^{23}$ These experiments then lead us to test this hypothesis in vivo, where we observed that C3aRA could in fact diminish Af-induced release of $\mathrm{C} 3$ in vitro. Pretreatment of mice with C3aRA effectively reduced sinonasal levels of C3a upon Af stimulation in sensitized mice. These data support a mechanism by which C3a activation stimulates C3a production through a $\mathrm{C} 3 \mathrm{a} / \mathrm{C} 3 \mathrm{aR}$ axis. We show that $\mathrm{C} 3 \mathrm{aR}$ expression is elevated in HSNEC from CRSwNP patients in vitro, perhaps suggesting that increased intracellular stores are in part modulated by increased C3aR expression and signaling.

Complement inhibition has become a clinical reality with the introduction of eculizumab for the treatment of paroxysmal nocturnal hemoglobinuria. ${ }^{77}$ Eculizumab functions by inhibiting C5 activation and is therefore considered safe for systemic administration as it leaves intact complement detection pathways, activation, and opsonin functions. ${ }^{78,79}$ While C3 inhibitors exist, such as compstatin, their utilization systemically is not without risk due to systemic complement functions. ${ }^{79}$ Fortunately, the sinus cavity lends itself anatomically to topical application. Here we demonstrated that $\mathrm{C} 3 \mathrm{a}$ receptor signaling through genetic deficiency, systemic antagonist inhibition, or local antagonist delivery provided protection from the development of CRS-like inflammation and epithelial injury. Complement anaphylatoxin deficiency and inhibition has been extensively studied, with blockade of $\mathrm{C} 3 \mathrm{a}$ and $\mathrm{C} 5 \mathrm{a}$ receptors shown to provide protection in rodent asthma models, such as house dust mite and ovalbumin and Af allergen challenge, and with $\mathrm{C} 3 \mathrm{a}$ and C5a shown to play differing roles in allergy induction and hypersensitivity. ${ }^{73}, 80,81$ While these model systems are very similar in their approach, none of these studies have previously investigated the upper respiratory tract, and none have accessed the impact of locally delivered receptor antagonist as therapeutic interventions. In these models, C3aR antagonism or deficiency is associated with reduced mucus hyperplasia, epithelial injury, and decreased small airway remodeling. ${ }^{81}$ Similarly, in our investigations in the upper airway, C3aR antagonism reduces hyperplasia, epithelial injury, and immune cell infiltration, all of which reduces CRS-like inflammation as determined by histological evaluation.

In conclusion, here we demonstrate that local sinonasal C3 concentrations are associated with disease severity, that HSNECs have intracellular stores of $\mathrm{C} 3$ that are present at supranormal 
levels in CRSwNP, and that these stores are quickly mobilized into the extracellular space upon stimulation. Building upon these findings we demonstrated that in vivo local sinonasal inhibition of $\mathrm{C} 3 \mathrm{a} / \mathrm{C} 3 \mathrm{aR}$ axis in a mouse model of CRS-like inflammation lead to reduction in pro-inflammatory cytokine and type 2 cytokine release. Finally, we demonstrate the therapeutic potential of local sinonasal complement inhibition as a means to modulate local inflammation and the development of CRS, a strategy that will likely protect systemic and local complement immune functions.

\section{ACKNOWLEDGEMENTS}

These studies were funded by grants from the NIH to C.A. (R01HL091944), Flight Attendants Medical Research Institute Clinical Innovator award 092079 (C.A.) and 92401 (J.K.M.). J.K.M. is supported by the South Carolina Clinical \& Translational Research (SCTR) Institute, with an academic home at the Medical University of South Carolina, NIH/NCATS Grant Numbers KL2 TR001452 and UL1 TR001450. This work was supported in part by core funds from the Hollings Cancer Center, Medical University of South Carolina (P30 CA138313), and the MUSC Proteomics Center, South Carolina Centers for Economic Excellence SmartState program. B.A.N. was supported in part by an award to the South Carolina SmartState Center of Economic Excellence in Proteomics, the Medical University of South Carolina Proteomics Center, and P20GM103542 from the NIGMS.

\section{ADDITIONAL INFORMATION}

The online version of this article (https://doi.org/10.1038/s41385-018-0048-x) contains supplementary material, which is available to authorized users.

Competing interests: The authors declare no competing interests.

Disclaimer: Identification of certain commercial equipment, instruments, software, or materials does not imply recommendation or endorsement by the National Institute of Standards and Technology, nor does it imply that the products identified are necessarily the best available for the purpose.Informed consentThe Medical University of South Carolina Institutional Review Board granted approval prior to initiation of the study and informed written consent was obtained from all participants. All procedures were approved by the Institutional Animal Care and Use Committee at the Medical University of South Carolina, in accordance with the National Institutes of Health Guide for the Care and Use of Laboratory Animals.

\section{REFERENCES}

1. Benninger, M. S. et al. Adult chronic rhinosinusitis: definitions, diagnosis, epidemiology, and pathophysiology. Otolaryngol. Head Neck Surg. 129(Suppl. 1), S1-S32 (2003).

2. Chan, Y. \& Kuhn, F. A. An update on the classifications, diagnosis, and treatment of rhinosinusitis. Curr. Opin. Otolaryngol. Head Neck Surg. 17, 204-208 (2009).

3. Mulligan, J. K. et al. Cigarette smoke exposure is associated with vitamin D3 deficiencies in patients with chronic rhinosinusitis. J. Allergy Clin. Immunol. 134, 342-349 (2014).

4. Bachert, $C$. et al. The role of cytokines in infectious sinusitis and nasal polyposis. Allergy 53, 2-13 (1998).

5. Schleimer, R. P. et al. Epithelium, inflammation, and immunity in the upper airways of humans: studies in chronic rhinosinusitis. Proc. Am. Thorac. Soc. 6, 288-294 (2009).

6. Tieu, D. D., Kern, R. C. \& Schleimer, R. P. Alterations in epithelial barrier function and host defense responses in chronic rhinosinusitis. J. Allergy Clin. Immunol. 124, 37-42 (2009).

7. Basinski, T. M. et al. Dual nature of T cell-epithelium interaction in chronic rhinosinusitis. J. Allergy Clin. Immunol. 124, 74-80.e78 (2009).

8. Davis, K. S. et al. Murine complement deficiency ameliorates acute cigarette smoke-induced nasal damage. Otolaryngol. Head Neck Surg. 143, 152-158 (2010).

9. Schlosser, R. J. et al. Alterations in gene expression of complement components in chronic rhinosinusitis. Am. J. Rhinol. Allergy 24, 21-25 (2010).

10. Lane, A. P., Truong-Tran, Q. A. \& Schleimer, R. P. Altered expression of genes associated with innate immunity and inflammation in recalcitrant rhinosinusitis with polyps. Am. J. Rhinol. 20, 138-144 (2006).

11. Van Roey, G. A. et al. Classical complement pathway activation in the nasal tissue of patients with chronic rhinosinusitis. J. Allergy Clin. Immunol. 140, 89-100.e2 (2016).

12. Miyaguchi, M., Uda, H., Sakai, S., Kubo, T. \& Matsunaga, T. Immunohistochemical studies of complement receptor (CR1) in cases with normal sinus mucosa and chronic sinusitis. Arch. Otorhinolaryngol. 244, 350-354 (1988).
13. Ogunleye, A. O. \& Arinola, O. G. Immunoglobulin classes, complement factors and circulating immune complexes in chronic sinusitis patients. Afr. J. Med. Med. Sci. 30, 309-312 (2001).

14. Van Roey, G. A. et al. Classical complement pathway activation in the nasal tissue of patients with chronic rhinosinusitis. J. Allergy Clin. Immunol. 140, 89-100.e102 (2017).

15. Ricklin, D., Mastellos, D. C., Reis, E. S. \& Lambris, J. D. The renaissance of complement therapeutics. Nat. Rev. Nephrol. 14, 26-47 (2018).

16. Fujita, T., Endo, Y. \& Nonaka, M. Primitive complement system-recognition and activation. Mol. Immunol. 41, 103-111 (2004).

17. Walport, M. J. Complement. First of two parts. N. Engl. J. Med. 344, 1058-1066 (2001).

18. Walport, M. J. Complement. Second of two parts. N. Engl. J. Med. 344, 1140-1144 (2001).

19. Kolev, M., Le Friec, G. \& Kemper, C. The role of complement in CD4(+) T cell homeostasis and effector functions. Semin. Immunol. 25, 12-19 (2013).

20. Heeger, P. S. \& Kemper, C. Novel roles of complement in T effector cell regulation. Immunobiology 217, 216-224 (2012).

21. Heeger, P. S. et al. Decay-accelerating factor modulates induction of $\mathrm{T}$ cell immunity. J. Exp. Med. 201, 1523-1530 (2005).

22. Kolev, M. et al. Complement regulates nutrient influx and metabolic reprogramming during Th1 cell responses. Immunity 42, 1033-1047 (2015).

23. Liszewski, M. K. et al. Intracellular complement activation sustains T cell homeostasis and mediates effector differentiation. Immunity 39, 1143-1157 (2013).

24. Pratt, J. R., Harmer, A. W., Levin, J. \& Sacks, S. H. Influence of complement on the allospecific antibody response to a primary vascularized organ graft. Eur. J. Immunol. 27, 2848-2853 (1997).

25. Pratt, J. R., Basheer, S. A. \& Sacks, S. H. Local synthesis of complement component C3 regulates acute renal transplant rejection. Nat. Med. 8, 582-587 (2002).

26. Reh, D. D. et al. Secondhand tobacco smoke exposure and chronic rhinosinusitis: a population-based case-control study. Am. J. Rhinol. Allergy 23, 562-567 (2009).

27. Tammemagi, C. M., Davis, R. M., Benninger, M. S., Holm, A. L. \& Krajenta R. Secondhand smoke as a potential cause of chronic rhinosinusitis: a case-control study. Arch. Otolaryngol. Head Neck Surg. 136, 327-334 (2010).

28. Yamin, M. et al. Cigarette smoke combined with Toll-like receptor 3 signaling triggers exaggerated epithelial regulated upon activation, normal T-cell expressed and secreted/CCL5 expression in chronic rhinosinusitis. J. Allergy Clin. Immunol. 122, 1145-1153 e1143 (2008).

29. Jun, S. W. et al. Overexpression of the anaphylatoxin receptors, complement anaphylatoxin 3a receptor and complement anaphylatoxin 5a receptor, in the nasal mucosa of patients with mild and severe persistent allergic rhinitis. J. Allergy Clin. Immunol. 122, 119-125 (2008).

30. Vandermeer, J., Sha, Q., Lane, A. P. \& Schleimer, R. P. Innate immunity of the sinonasal cavity: expression of messenger RNA for complement cascade components and toll-like receptors. Arch. Otolaryngol. Head. Neck Surg. 130, 1374-1380 (2004).

31. Xia, L., Wang, Y., Gao, W. \& Gao, H. [Expression of CD55 and CD59 in chronic rhinosinusitis and its significance]. Zhonghua. Er. Bi. Yan. Hou. Tou. Jing. Wai. Ke. Za. Zhi. 49, 1021-1023 (2014).

32. Gaunsbaek, M. Q. et al. Complement defects in patients with chronic rhinosinusitis. PLOS ONE 7, e47383 (2012).

33. Cui, Y. H. et al. Increased serum complement component 3 and mannose-binding lectin levels in adult Chinese patients with chronic rhinosinusitis. Rhinology 47, 187-191 (2009).

34. Seppanen, M. et al. Immunoglobulins and complement factor C4 in adult rhinosinusitis. Clin. Exp. Immunol. 145, 219-227 (2006).

35. Fokkens, W. J. et al. EPOS 2012: European position paper on rhinosinusitis and nasal polyps 2012. A summary for otorhinolaryngologists. Rhinology 50, 1-12 (2012).

36. Mulligan, J. K., Mulligan, R. M., Atkinson, C. \& Schlosser, R. J. Human sinonasal epithelial cells direct dendritic cell function and T-cell $T$ helper $1 / T$ helper 2 skewing following Aspergillus exposure. Int. Forum Allergy Rhinol. 1, 268-274 (2011).

37. Mulligan, J. K., Mulligan, R. M., Atkinson, C. \& Schlosser, R. J. Human sinonasal epithelial cells direct dendritic function and T-cell T helper $1 / T$ helper 2 skewing following Aspergillus exposure. Int. Forum Allergy Rhinol. 1, 268-274 (2011).

38. Rehl, R. M. et al. Mucosal remodeling in chronic rhinosinusitis. Am. J. Rhinol. 21, 651-657 (2007).

39. Schlosser, R. J., et al. Mucous cytokine levels in chronic rhinosinusitis-associated olfactory loss. JAMA Otolaryngol. Head Neck Surgery 142, 731-7 (2016).

40. Sansoni, E. R. et al. Vitamin D3 as a novel regulator of basic fibroblast growth factor in chronic rhinosinusitis with nasal polyposis. Int. Forum Allergy Rhinol. 5, 191-196 (2015)

41. Banglawala, S. M. et al. Impact of intraoperative hydrodebrider treatment on postoperative sinonasal inflammation. Am. J. Rhinol. Allergy 28, 438-442 (2014). 
42. Oyer, S. L., Mulligan, J. K., Psaltis, A. J., Henriquez, O. A. \& Schlosser, R. J. Cytokine correlation between sinus tissue and nasal secretions among chronic rhinosinusitis and controls. Laryngoscope 123, E72-E78 (2013).

43. Denning, D. W. et al. High-frequency triazole resistance found In nonculturable Aspergillus fumigatus from lungs of patients with chronic fungal disease. Clin. Infect. Dis. 52, 1123-1129 (2011).

44. Mullins, J. \& Seaton, A. Fungal spores in lung and sputum. Clin. Allergy 8, 525-533 (1978).

45. Park, S. J. \& Mehrad, B. Innate immunity to Aspergillus species. Clin. Microbiol. Rev. 22, 535-551 (2009).

46. Tomee, J. F. C., Wierenga, A. T. J., Hiemstra, P. S. \& Kauffman, H. F. Proteases from Aspergillus fumigatus induce release of proinflammatory cytokines and cell detachment in airway epithelial cell lines. J. Infect. Dis. 176, 300-303 (1997).

47. Borger, P. et al. Proteases from Aspergillus fumigatus induce interleukin (IL)- 6 and IL-8 production in airway epithelial cell lines by transcriptional mechanisms. J. Infect. Dis. 180, 1267-1274 (1999).

48. Mulligan, J. K., et al. Impact of tobacco smoke on upper airway dendritic cell accumulation and regulation by sinonasal epithelial cells. Int. Forum Allergy Rhinol. 7, 777-785 (2017).

49. Lawrence, L. A. et al. Superoxide dismutase reduces the inflammatory response to Aspergillus and Alternaria in human sinonasal epithelial cells derived from patients with chronic rhinosinusitis. Am. J. Rhinol. Allergy 29, 89-93 (2015).

50. Bleier, B. S., Mulligan, R. M. \& Schlosser, R. J. Primary human sinonasal epithelial cell culture model for topical drug delivery in patients with chronic rhinosinusitis with nasal polyposis. J. Pharm. Pharmacol. 64, 449-456 (2012).

51. Khalid, A. N. et al. Physiologic alterations in the murine model after nasal fungal antigenic exposure. Otolaryngol. Head. Neck Surg. 139, 695-701 (2008).

52. Wang, $H$. et al. Histological and immunological observations of bacterial and allergic chronic rhinosinusitis in the mouse. Am. J. Rhinol. 22, 343-348 (2008).

53. Kim, J. H., Yi, J. S., Gong, C. H. \& Jang, Y. J. Development of Aspergillus protease with ovalbumin-induced allergic chronic rhinosinusitis model in the mouse. Am. J. Rhinol. Allergy 28, 465-470 (2014).

54. Kim, D. W. et al. Staphylococcus aureus enterotoxin B contributes to induction of nasal polypoid lesions in an allergic rhinosinusitis murine model. Am. J. Rhinol. Allergy 25, e255-e261 (2011).

55. Lane, A. P., Truong-Tran, Q. A., Myers, A., Bickel, C. \& Schleimer, R. P. Serum amyloid A, properdin, complement 3 , and toll-like receptors are expressed locally in human sinonasal tissue. Am. J. Rhinol. 20, 117-123 (2006).

56. Bolger, M. S. et al. Complement levels and activity in the normal and LPS-injured lung. Am. J. Physiol. Lung Cell. Mol. Physiol. 292, L748-L759 (2007).

57. Ayers, C. M. et al. Increased presence of dendritic cells and dendritic cell chemokines in the sinus mucosa of chronic rhinosinusitis with nasal polyps and allergic fungal rhinosinusitis. Int. Forum Allergy Rhinol. 1, 296-302 (2011).

58. Liao, B., et al. Multidimensional endotypes of chronic rhinosinusitis and their association with treatment outcomes. Allergy (2018).

59. Alt, J. A., Sautter, N. B., Mace, J. C., Detwiller, K. Y. \& Smith, T. L. Antisomnogenic cytokines, quality of life, and chronic rhinosinusitis: a pilot study. Laryngoscope 124, E107-E114 (2014).

60. Perić, A., Vojvodić, D., Perić, A. V., Radulović, V. \& Miljanović, O. Correlation between cytokine levels in nasal fluid and scored clinical parameters in patients with nasal polyposis. Indian J. Otolaryngol. Head. Neck Surg. 65(Suppl. 2), 295-300 (2013).

61. Divekar, R. D. et al. Immunological profiling in chronic rhinosinusitis with nasal polyps reveals distinct VEGF and GM-CSF signatures during symptomatic exacerbations. Clin. Exp. Allergy. 45, 767-778 (2015).
62. Tomazic, P. V. et al. Nasal mucus proteomic changes reflect altered immune responses and epithelial permeability in patients with allergic rhinitis. J. Allergy Clin. Immunol. 133, 741-750 (2014).

63. Varsano, S., Kaminsky, M., Kaiser, M. \& Rashkovsky, L. Generation of complement C3 and expression of cell membrane complement inhibitory proteins by human bronchial epithelium cell line. Thorax 55, 364-369 (2000).

64. Sunderhauf, A. et al. Regulation of epithelial cell expressed C3 in the intestinerelevance for the pathophysiology of inflammatory bowel disease? Mol. Immunol. 90, 227-238 (2017).

65. Satyam, A., et al. Intracellular activation of complement 3 is responsible for intestinal tissue damage during mesenteric ischemia. J. Immunol. 198, 788-797 (2017).

66. Elvington, M., Liszewski, M. K., Bertram, P., Kulkarni, H. S. \& Atkinson, J. P. A C3 $(\mathrm{H} 20)$ recycling pathway is a component of the intracellular complement system. J. Clin. Invest. 127, 970-981 (2017).

67. Reddy, V. B. \& Lerner, E. A. Activation of mas-related G-protein coupled receptors by the house dust mite cysteine protease Der p1 provides a new mechanism linking allergy and inflammation. J. Biol. Chem. 292, 17399-17406 (2017).

68. Wills-Karp, M. Allergen-specific pattern recognition receptor pathways. Curr. Opin. Immunol. 22, 777-782 (2010).

69. Rosbjerg, A. et al. Complementary roles of the classical and lectin complement pathways in the defense against Aspergillus fumigatus. Front. Immunol. 7, 473 (2016).

70. Speth, C. \& Rambach, G. Complement attack against Aspergillus and corresponding evasion mechanisms. Interdiscip. Perspect. Infect. Dis. 2012, 463794 (2012).

71. Hartmann, K. et al. C3a and C5a stimulate chemotaxis of human mast cells. Blood 89, 2863-2870 (1997).

72. Kemper, C. \& Kohl, J. Novel roles for complement receptors in T cell regulation and beyond. Mol. Immunol. 56, 181-190 (2013).

73. Mizutani, N., Nabe, T. \& Yoshino, S. Complement C3a regulates late asthmatic response and airway hyperresponsiveness in mice. J. Immunol. 183, 4039-4046 (2009).

74. Raedler, H., Yang, M., Lalli, P. N., Medof, M. E. \& Heeger, P. S. Primed CD8(+) T-cell responses to allogeneic endothelial cells are controlled by local complement activation. Am. J. Transplant. 9, 1784-1795 (2009).

75. Lalli, P. N., Strainic, M. G., Lin, F., Medof, M. E. \& Heeger, P. S. Decay accelerating factor can control T cell differentiation into IFN-gamma-producing effector cells via regulating local C5a-induced IL-12 production. J. Immunol. 179, 5793-5802 (2007).

76. Kwan, W. H. et al. Antigen-presenting cell-derived complement modulates graftversus-host disease. J. Clin. Invest. 122, 2234-2238 (2012).

77. Risitano, A. M. \& Marotta, S. Therapeutic complement inhibition in complementmediated hemolytic anemias: Past, present and future. Semin. Immunol. 28, 223-240 (2016).

78. Subias Hidalgo, M. et al. Extravascular hemolysis and complement consumption in paroxysmal nocturnal hemoglobinuria patients undergoing eculizumab treatment. Immunobiology 222, 363-371 (2017).

79. Ricklin, D., Reis, E. S., Mastellos, D. C., Gros, P. \& Lambris, J. D. Complement component C3-the "Swiss Army Knife" of innate immunity and host defense. Immunol. Rev. 274, 33-58 (2016).

80. Kohl, J. et al. A regulatory role for the C5a anaphylatoxin in type 2 immunity in asthma. J. Clin. Invest. 116, 783-796 (2006).

81. Zhang, $\mathrm{X}$. et al. A protective role for $\mathrm{C} 5 \mathrm{a}$ in the development of allergic asthma associated with altered levels of B7-H1 and B7-DC on plasmacytoid dendritic cells. J. Immunol. 182, 5123-5130 (2009). 